\title{
AGENESIS OF GALL BLADDER DIAGNOSED INTRA-OPERATIVELY: A CASE REPORT
}

N. Somorjit Singh, A. Ranjita Devi, Ramthaipui Kamei, K. Rupachand Sharma

\author{
1. Assistant Professor. Department of General Surgery, Jawaharlal Nehru Institute of Medical Sciences, \\ Imphal, Manipur. \\ 2. Assistant Professor. Department of General Surgery, Jawaharlal Nehru Institute of Medical Sciences, \\ Imphal, Manipur. \\ 3. Senior Resident. Department of General Surgery, Jawaharlal Nehru Institute of Medical Sciences, Imphal, \\ Manipur. \\ 4. Consultant Surgeon. Department of General Surgery, Jawaharlal Nehru Institute of Medical Sciences, \\ Imphal, Manipur.
}

\section{CORRESPONDING AUTHOR:}

Dr. N. Somorjit Singh,

Keisanthong Elangbam Leikai,

Leirak Achouba, Imphal,

Manipur, Pin -795001.

E-mail: drnssingh@yahoo.com

ABSTRACT : BACKGROUND : Congenital absence of GB is a rare anomaly occurring in less than 1 in 1000 population. These patients' complaints of those of more common biliary conditions and routine radiological and biochemical investigation makes difficult to diagnose preoperatively and patients undergo unnecessary operative intervention. MATERIALS AND METHODS : A 18 years old female with clinical features of Cholecystitis diagnosed by USG as Contracted GB with Cholelithiasis was operated for Open Cholecystectomy. Intra-operatively, the GB could not be seen even after thorough dissection. Post operative MRCP confirmed the diagnosis of absence of GB. RESULTS: The patient having the classical features of Gall Stone disease with the routine investigative reports, had undergone Operation .As the gall bladder was not found, the procedure was terminated and post operative MRCP confirmed the diagnosis of absence of GB. CONCLUSION: The rare congenital anomaly of absence of GB may have common biliary conditions, and so patients may undergo unnecessary operative procedures. With the newer minimally invasive radiologic techniques, this situation can largely be avoided if awareness of this condition is improved.

KEY WORDS: Gallbladder, Absence, Congenital, WES, MRCP

INTRODUCTION: Congenital absence of the GB is a rare anomaly due to failure of the cystic bud to develop in utero. The incidence is of $0.13-0.75 \%(<1: 1000)$ with a sex ratio of Male: Female of 3:1. Clinically, these patients may be asymptomatic or symptomatic. If symptomatic, the patient may have features of suspicious Cholecystitis. Routine USG abdomen may show shrunken /contracted GB with streaks of echogenic shadow.

In our patient, with the clinical findings of Cholecystitis and routine USG findings of contracted GB having streaks of echogenic shadow diagnosed as Contracted GB with Cholelithiasis.The patient underwent operation where there was no GB and makes the surgeon in awkward position .

MATERIALS AND METHODS: A 18 years old female admitted in the Surgery Ward of $J N$ INSTITUTE OF MEDICAL SCIENCAL HOSPITAL, IMPHAL MANIPUR on 27th April 2011 ( Hospital 
no 52055 ) with severe upper abdominal pain associated with nausea and vomiting .She had similar episodes for the last 6 months.

Clinical examination revealed a tender Right hypochondrium and positive Murphy's sign and made the diagnosis of cholecystitis. Other systemic Examination are normal . Blood investigations were within normal limits.

USG abdomen shows hyperechoic shadows in the GB fossa ( WES Sign i.e. wall echo shadow ) suggestive of contracted GB with Cholelithiasis with normal biliary tract. Considering as a case of Contracted GB with Cholelithiasis, we underwent open cholecystectomy but GB was not found even with a meticulous search with proper dissection .No CBD exploration or intraoperative cholangiography done as it will significantly increased the morbidity without contributing to the diagnosis. We stopped the procedure at this stage and decided to performed post operative MRCP (Magnetic Resonance Cholangio-Pancreatography) to confirm the diagnosis of the congenital absence of GB and to rule out an ectopic GB.

Post operatively MRCP done which failed to demonstrate a Gall Bladder (which confirms the diagnosis of the absence of Gall Bladder)

RESULTS/DISCUSSION: Congenital absence of the GB is a rare finding with reported incidence of 0.01 to $0.075 \%$ [1-4]. Though many of these patients are asymptomatic, $34 \%$ of the patients in the review of 44 cases of the congenital absence of the GB had dyspeptic symptoms and $54 \%$ had symptoms suggestive of biliary colic [5]. 12 patients even had jaundice but only 8 of these 12 patients had CBD stones. It has been suggested that congenital absence of GB can predispose to an increase incidence of CBD stones [6,7]

Our patients though with normal biochemical results had dyspeptic symptoms and pain in the right hypochondrium similar to that occurring in Cholecystitis.

Various authors [ 1,2,5,6,8-11] have found USG to be misleading in interpreting a Contracted and fibrotic GB. Our experience was very similar. Most symptomatic patients are scheduled for Surgery with a diagnosis of chronic Cholecystitis with a contracted fibrosed GB and normal biliary tract. With little awareness of these rare conditions with overenthusiastic surgeons may cause more iatrogenic injury for searching the GB leading to increase morbidity to the patients.

Recent literature suggests that CT and ERCP are useful postoperative modalities, if gallbladder agenesis is suspected at laparoscopy [12]. In this instance, laparotomy and extensive dissection to look for the missing gallbladder are discouraged, and instead, postoperative imaging is advised [13].With the newer non-invasive imaging modalities like CT , MRCP, ERCP or EUS provides an excellent alternative to open exploration and intra-operative cholangiography. EUS has been shown to be useful in detecting anomalies in the extra hepatic biliary tree.

CONCLUSION: Congenital absence of the GB makes the Surgeon in dilemma as it is often diagnosed intra-operatively. The tendency to proceed to open exploration of the biliary tree should be avoided especially when no other known pathology in the biliary tree is present. Congenital absence of GB should be kept in mind whenever GB is improperly visualised in the routine imaging methods i.e. USG.

Surgeons should maintain a low threshold as clinical and radiologic features mimic those of more common biliary conditions. With the newer minimally invasive radiologic techniques, this situation can largely be avoided if awareness of this condition is improved. 


\section{REFERENCES:}

1. Vijay KT, Kocher HH, Koti RS, Bapat RD. Agenesis of gallbladder: a diagnostic dilemma. J Postgrad Med. 1996;42(3):80-82.

2. Cho $\mathrm{CH}$, Suh KW, Min JS, Kim CK. Congenital absence of gallbladder. Yonsei Med J. 1992;33(4):364 -366.

3. Bennion RS, Thompson JE Jr., Tompkins RK. Agenesis of the gallbladder without extrahepatic biliary atresia. Arch Surg. 1988;123(10):1257-1260.

4. Singh B, Satyapal KS, Moodley J, Haffejee AA. Congenital absence of the gall bladder. Surg Radiol Anat. 1999;21(3):221-224.

5. Richards RJ, Taubin $\mathrm{H}$, Wasson D. Agenesis of the gallbladder in symptomatic adults. A case and review of the literature.J Clin Gastroenterol. 1993;16(3):231-233

6. Peloponissiois N, Gillet M, Cavin R, Halkic N. Agenesis of the gallbladder: a dangerously misdiagnosed malformation. World JGastroenterol. 2005;11(39):6228-6231.

7. Kabiri H, Domingo OH, Tzarnas CD. Agenesis of the gallbladder. Curr Surg. 2006;63(2): $104-106$.

8. Jackson RJ, McClellan D. Agenesis of the gallbladder. A cause of false positive ultrasonography. Am Surg. 1989;55(1):36-40.

9. Ibrarullah M, Sikora SS, Kapoor VK, Awasthi S, Kacker LK. Agenesis of the gallbladder- a case report. Jpn J Surg. 1991;21(5):580-582.

10. Jain BK, Das DN, Singh RK, Kukreti R, Dargan P. Agenesis of gallbladder in symptomatic patients. Trop Gastroenterol. 2001; 22(2):80-82

11. Baltazar U, Dunn J, Gonzalez Diaz S, Bowder W. Agenesis of the gallbladder. South Med J. 2000;93(9):914-915.

12. Grandhi TM, El-Rabaa SM: Agenesis of the gall bladder and cystic duct: laparoscopic diagnosis. Int J Gastroenterol 2005., 4(1):285

13. Balakrishnan S, Singhal T, Grandy-Smith S, El-Hasani S: Agenesis of the gallbladder: lessons to learn. JSLS 2006, 10:517-519.PubMed Abstract/Publisher Full Text 

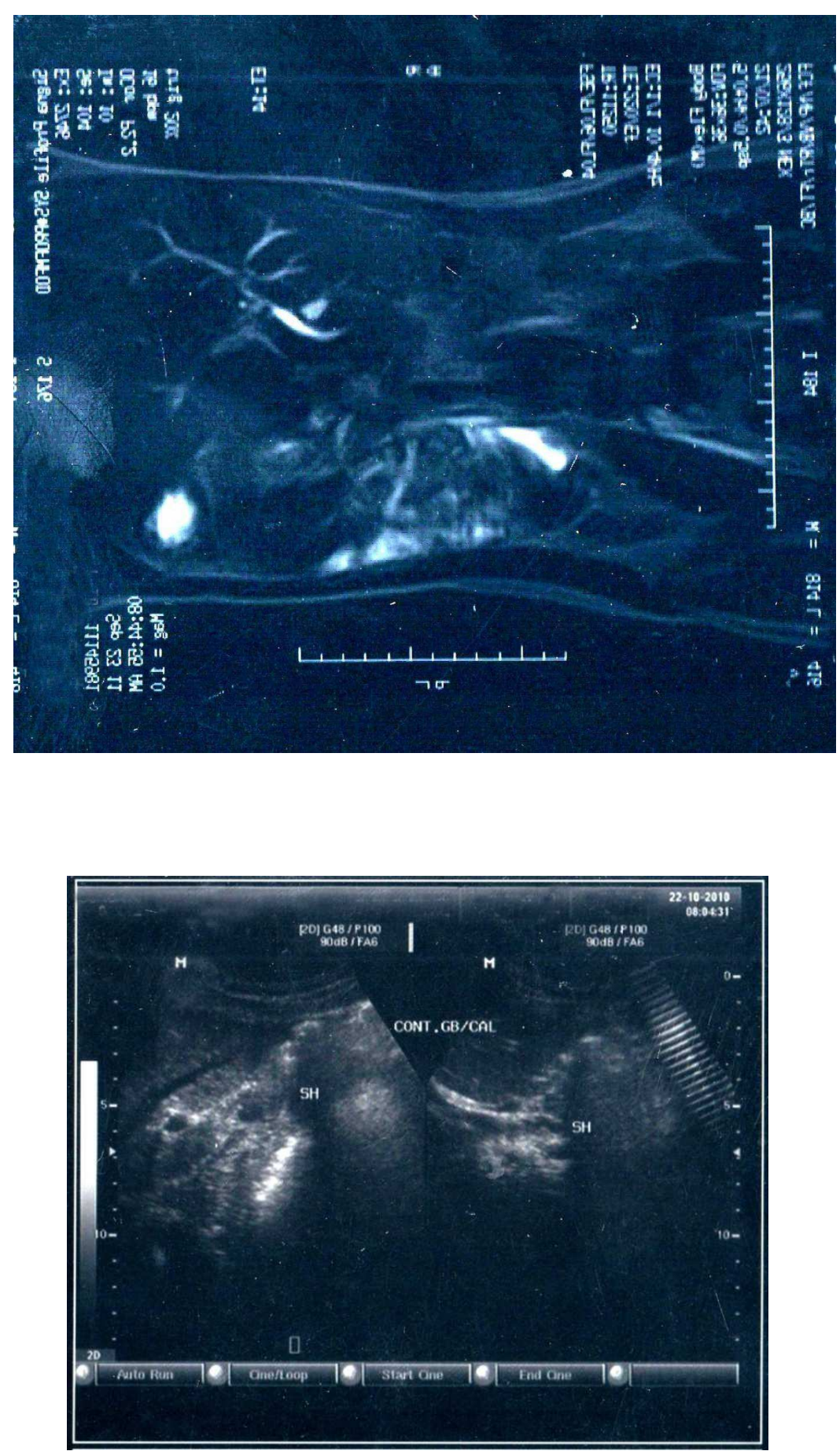